\title{
KNOWLEDGE, INNOVATION, AND THE ROLE OF GOVERNMENT IN THE CIRCULAR BIOECONOMY
}

\author{
$\underline{\text { Antonio R. Hurtado }}^{\mathrm{a}, \mathrm{b}, *}$, Julio Berbel ${ }^{\mathrm{b}}$ \\ ${ }^{a}$ Lviv Business School, Ukrainian Catholic University (Lviv, Ukraine, ahurtado@lvbs.com.ua). ${ }^{b}$ WEARE- \\ Water, Environmental, and Agricultural Resources Economics, Universidad de Córdoba (Córdoba, \\ berbel@uco.es).
}

\begin{abstract}
Competitiveness and innovation performance depend not only on the skills that the different actors of an innovation system can find, develop, and exploit internally, but also on the efficiency with which they can access external sources of knowledge and skills related to technologies and markets. This acquires greater importance in the case of the bioeconomy because it is a sector that is intensive in knowledge and innovation, and because of its position at the confluence of several technological areas. As a result, there has been growing interest in understanding the interventions in the innovation system that are more likely to positively impact its role in the creation and delivery of value to markets and society. Thus, for this study, system dynamics modelling methods are used to examine the Andalusian Circular Bioeconomy Strategy. An analysis is made of how knowledge and learning influence the performance of the circular bioeconomyrelated innovation system, and 22 leverage points are preliminarily identified where interventions could enhance strengths and overcome weaknesses. Overall, our preliminary findings show that the role of government in supporting learning and knowledge-related processes is key for the development of the circular bioeconomy due to the pervasiveness of information asymmetry in the sector.
\end{abstract}

Keywords: Bioeconomy, knowledge, innovation, learning, system dynamics.

\section{Introduction and Objectives}

A strong innovation ecosystem based on a balance between science and technology push and market and social pull will play a leading role in the realization of the potential presented by the circular bioeconomy (CBE). In this context, the dynamics of learning and innovation are critical as the bioeconomy sector is largely composed of companies with persistently low levels of digitalization (Bacco et al., 2019) and struggling to develop effective business models (Reim et al., 2019).

Assessing and measuring the underlying processes of learning and knowledge accumulation has been an ongoing challenge for decades (Abramovitz, 1956; Dosi et al., 1988; Romer, 1990; Solow, 1957). This has had important repercussions for technology, innovation, and economic development policymaking, which has strongly relied on a linear R\&D-based innovation model. However, the literature on the topic is increasingly recognizing external knowledge sources as key elements of the innovation process (Doloreux et al., 2020; Fitjar and Rodríguez-Pose, 2013; Isaksen and Nilsson, 2013; Jensen et al., 2007; Santner, 2018).

Against this backdrop, this study seeks to contribute to the understanding of how the dynamics of innovation systems influence the development of the CBE, exploring how knowledge and learning influence the performance of these systems, and identifying points where interventions could enhance the strengths and overcome the weaknesses to promote growth in this sector of the economy.

\section{Methodology}

We apply system dynamics modelling methods (Meadows, 2008; Sterman, 2000) to analyze Andalusia's CBE-related innovation system and to conduct a qualitative assessment of key learning- and knowledgerelated intervention points to develop this sector.

The first step consisted in reviewing the literature related to the application of systems thinking to the study of innovation and the bioeconomy, with the objective of identifying the factors that influence performance in these areas. A review of the literature on the Andalusian bioeconomy and innovation system was performed simultaneously, to gain a perspective of the regional context.

The information thus obtained was subsequently used to develop a primary conceptual model of Andalusia's CBE-related innovation system, using causal loop diagrams (CLDs) designed with Vensim PLE software (Ventana Systems, 2021) to represent the causal relationships, identify reinforcing and balancing processes within the system, and find potential leverage points related to knowledge and learning. This study focuses on the Andalusian Circular Bioeconomy Strategy (ACBS) (Regional Government of Andalusia, 2018) and consequently we adopt the scope therein used to define the CBE, i.e. primary and 
agro-industrial activities aimed at producing food for human consumption are not included. Food products are considered a resource for the CBE only if their non-compliance with regulations or loss of quality during their processing makes them unsuitable for human consumption.

\section{Results}

The data gathered from the literature review and analysis of the ACBS led to four conceptual CLDs portraying the causal relationships among the key factors, variables and indicators formulated in the four strategic lines of the ACBS: (1) sustainable generation and availability of biomass resources, (2) infrastructure and logistics management of biomass resources, (3) processing of biomass resources and capacity of industrial production of bioproducts and bioenergy, and (4) development of markets for bioproducts and bioenergy. These were subsequently merged into two integrated CLDs and a total of 22 leverage points (LPs) were preliminarily identified where interventions could have meaningful impact.

\subsection{Sustainable generation of biomass resources; development of industrial capacity to process biomass resources and generate bioproducts and bioenergy}

During the analysis of the ACBS, several reinforcing feedback loops (R1, R2, R3, and R4) were identified that would lead to higher "Availability of sustainable biomass resources" and increase the "Construction of new biorefineries and conversion of existing facilities", along with three delayed balancing feedback loops (B1, B2, and B3) that would work to stabilize the system (Figure 1).

Figure 1. Dynamics suggested to govern the sustainable generation of biomass resources as well as the development of industrial capacity to process biomass resources and obtain bioproducts and bioenergy.

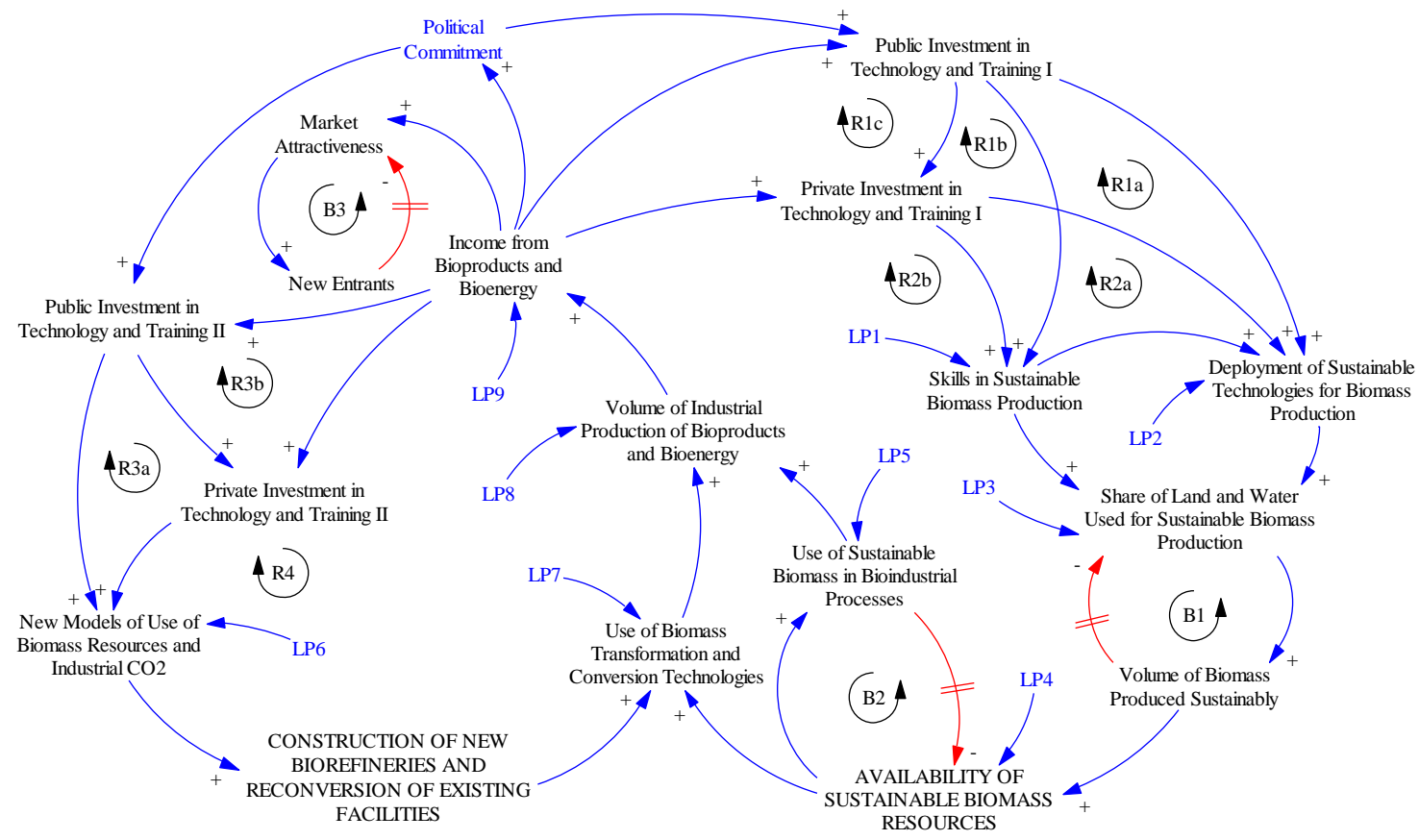

Of the 11 LPs portrayed in the integrated CLD above, three (LP1, LP2, and LP3) were related to the development of skills, the deployment of sustainable technologies, and the use of land and water resources for sustainable biomass production, all of which together would boost the volume of biomass produced sustainably. Examples of actions that could be implemented at these LPs include the development and updating of guidelines and best practices for the sustainable use of land and water, as well as technical reports related to current and upcoming technologies for sustainable biomass production. Subsequently, activities designed to enhance the sharing of knowledge regarding the biomass resources available (LP4) and how these are being used in bioindustrial processes (LP5) have the potential to increase the use of technologies for biomass transformation and conversion, which is concurrently potentiated by mechanisms designed to increase learning about new models of use of biomass resources and industrial $\mathrm{CO}_{2}$ (LP6). Lastly, as new biorefineries are built and existing facilities are reconverted both in the region and around the world, the Andalusian circular bioeconomy-related innovation system would benefit significantly from 
greater access to the growing global stock of knowledge about technologies for biomass transformation and conversion, the various types of bioproducts and bioenergy generated from these sources, and the rising income from these activities (LP7, LP8 and LP9). Above all of these, given that the CBE is an emerging sector that will require ongoing government support for some time, political commitment to public investments in technology and training is key for its success.

\subsection{Economic viability of biomass collection and storage; development of markets for bioproducts and bioenergy}

Several reinforcing feedback loops (R5 to R11) were identified that would lead to higher "Economic viability of biomass collection and storage" and boost the sales of bioproducts, bioenergy, and related bioeconomy services. Likewise, one delayed balancing feedback loop (B4) was found that would work to stabilize the system (Figure 2).

Figure 2. Causal loop diagram displaying the dynamics hypothesized to govern the economic viability of biomass collection and storage as well as development of markets for bioproducts and bioenergy.

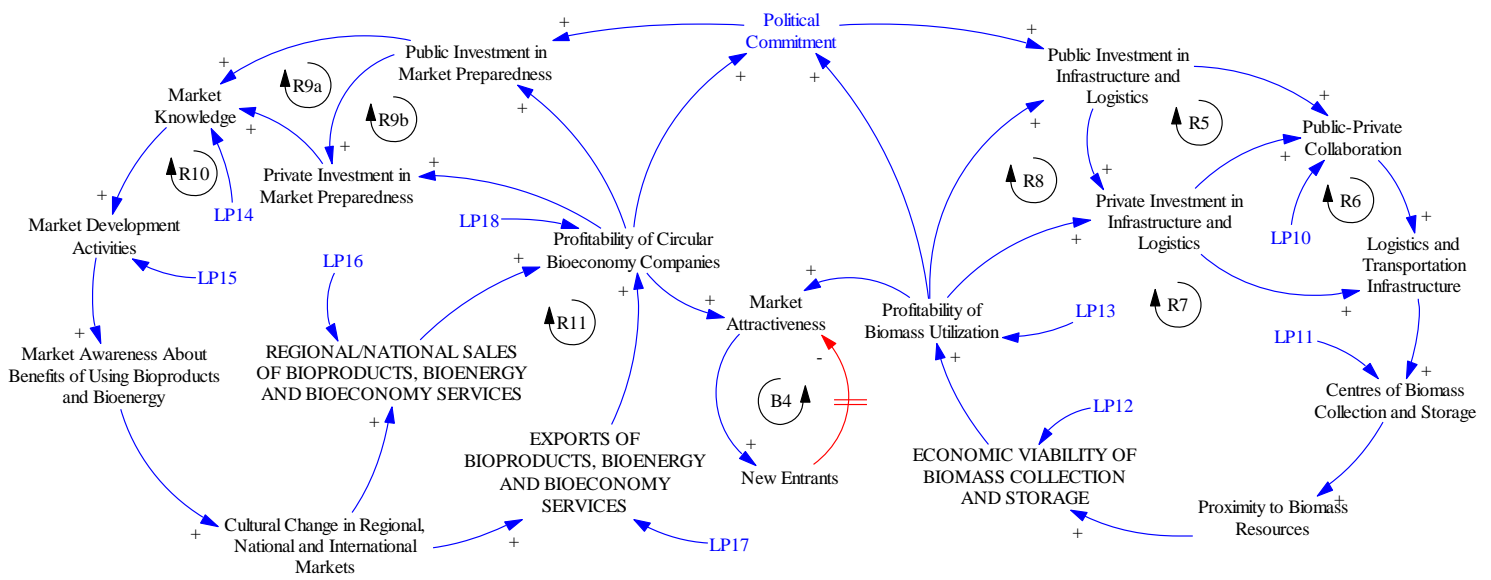

Of the 11 LPs identified for these two strategic lines of the ACBS, four (LP10 to LP13) were related to increasing the economic viability of biomass collection and storage. Examples of actions that could be implemented at these points of intervention include the development of inventories of biomass resources, technical reports about best practices for biomass collection and storage (including pre-treatment), and case studies of public-private collaboration for viable/profitable logistics and transportation of these resources. On the other hand, five LPs (LP14 to LP18) were linked to the commercialization of bioproducts, bioenergy, and bioeconomy services. In this regard, while a significant part of the activities contained in Figure 1 involve science, technology, and innovation (STI)-based learning processes, actions aimed at building structures and relationships to enhance the doing, using, and interacting (DUI) mode of learning are likely to have higher impact in this strategic line (Jensen et al., 2007; Thomä, 2017). Lastly, as noted in the previous figure, political commitment plays a pivotal role due to the emerging nature of the CBE sector.

\section{Conclusions}

The application of the system dynamics approach to the analysis of innovation processes in the CBE provides important insights into the complexity of these systems due to the existence of non-linear processes, multiple feedback loops, and time delays. Likewise, the models generated in this study provide tools for a better understanding of the potential impact that interventions by governments and other actors could have on different parts of the innovation systems and on the development of the CBE.

Overall, our preliminary findings show that the role of government in supporting learning and knowledgerelated processes is key for the development of the CBE due to the pervasiveness of information asymmetry in the sector, especially given its intensity in knowledge and innovation as well as its position at the confluence of several technological areas. As it has been postulated by Lin (2003), in this kind of scenario, the positive impact of government is higher when it seeks to help companies to overcome information and coordination costs about new industries, markets, and technologies as well as to compensate the markets for externalities produced by the pioneering firms. 
In the next step, the CLDs herein described will be enriched with factors and variables derived from the four complementing instrumental programs formulated in the ACBS. Subsequently, informal conversations and semi-structured interviews of experts and stakeholders will provide the empirical foundation of this study to gain insights into the actual dynamics of the system and validate the LPs identified to date. The insights thus obtained will then be used to make the appropriate adjustments and draw the final version of the CLDs.

\section{Bibliography}

Abramovitz, M. (1956). "Resource and output trends in the United States Since 1870". American Economic Review, 46:5-23.

Bacco, M., Barsocchi, P., Ferro, E., Gotta, A. and Ruggeri, M. (2019). "The digitisation of agriculture: a survey of research activities on smart farming". Array, 3-4:100009.

Doloreux, D., Shearmur, R., Porto-Gomez, I. and Zabala-Iturriagagoitia, J. M. (2020) "DUI and STI innovation modes in the Canadian wine industry: The geography of interaction modes". Growth and Change, 51(3):890-909.

Dosi, G., Freeman, C., Nelson, R., Silverberg, G. and Soete, L. (1988), Technical Change and Economic Theory, Laboratory of Economics and Management (LEM), Sant'Anna School of Advanced Studies, Pisa, Italy.

Fitjar, R.D. and Rodríguez-Pose, A. (2013). "Firm collaboration and modes of innovation in Norway". Research Policy, 42(1):128-138.

Isaksen, A. and Nilsson, M. (2013). "Combined innovation policy: Linking scientific and practical knowledge in innovation systems". European Planning Studies, 21(12):1919-1936.

Jensen, M.B., Johnson, B., Lorenz, E., and Lundvall, B.Å. (2007). "Forms of knowledge and modes of innovation". Research Policy, 36(5): 680-693.

Lin, J.Y. (2003). "Development strategy, viability, and economic convergence". Economic Development and Cultural Change, 51(2):277-308.

Meadows, D.H. (2008). Thinking in Systems: A Primer. Chelsea Green Publishing.

Regional Government of Andalusia. (2018). Andalusian Circular Bioeconomy Strategy. https://www.juntadeandalucia.es/export/drupaljda/Estrategia_Andaluza_Bioeconomia_Circular_E ABC_18.09.2018.pdf, accessed 25 January 2020.

Reim, W., Parida, V., and Sjödin, D.R. (2019). "Circular business models for the bio-economy: A review and new directions for future research". Sustainability, 11:2558.

Romer, P.M. (1990). “Endogenous technological change”. The Quarterly Journal of Economics, 98(5):S71S102.

Santner, D. (2018). "Proximity and modes of innovation-Evidence from two agricultural engineering industries in north-west Germany". European Planning Studies, 26(5): 877-894.

Solow, R.M. (1957). "Technical Change and the Aggregate Production Function". The Review of Economics and Statistics, 39(3):312-320.

Sterman, J.D. (2000). Business Dynamics: Systems Thinking and Modeling for a Complex World. Irwin/McGraw Hill.

Thomä, J. (2017). "DUI mode learning and barriers to innovation-A case from Germany". Research Policy, 46:1327-1339.

Ventana Systems (2021). Vensim PLE software, Ventana Systems Inc. Retrieved from http://www.vensim.com. 